\title{
Some Problems in Planetary Atmospheres Involving Collision Processes
}

\section{Citation}

Dalgarno, A. 1967. "Some Problems in Planetary Atmospheres Involving Collision Processes." Reviews of Modern Physics 39 (4) (October 1): 858-861. doi:10.1103/revmodphys.39.858. http:// dx.doi.org/10.1103/RevModPhys.39.858.

\section{Published Version}

doi:doi.org/10.1103/RevModPhys.39.858

\section{Permanent link}

http://nrs.harvard.edu/urn-3:HUL.InstRepos:29914186

\section{Terms of Use}

This article was downloaded from Harvard University's DASH repository, and is made available under the terms and conditions applicable to Other Posted Material, as set forth at http:// nrs.harvard.edu/urn-3:HUL.InstRepos:dash.current.terms-of-use\#LAA

\section{Share Your Story}

The Harvard community has made this article openly available.

Please share how this access benefits you. Submit a story.

\section{Accessibility}




\title{
Some Problems in Planetary Atmospheres Involving Collision Processes"
}

\author{
A. DALGARNO $\uparrow$ \\ School of Physics and Applied Mathematics, The Queen's University, Belfast, Northern Ireland
}

A brief selection of problems occurring in the interpretation of planetary atmospheres, the resolution of which demands a knowledge of atomic collision processes, is presented. The selection is largely arbitrary.

The interpretation of phenomena occurring in the atmospheres of the planets requires a knowledge of the rates of a large variety of atomic collision processes. In this summary, we select some of the more significant problems posed by our present understanding of the atmospheres of the planets Earth and Mars.

Substantial progress has been made during the last decade in the laboratory determination of the rates of the thermal chemical reactions which determine the structure of the atmosphere and ionosphere of the planet Earth, and comprehensive reviews have appeared of the laboratory measurements of reactions involving oxygen and nitrogen (Schiff 1964) and involving hydrogen (Kaufman 1964). Most of the measurements refer to a narrow temperature region about room temperature and efforts to extend the temperature range to that occurring in the atmosphere $\left(150^{\circ}-3000^{\circ} \mathrm{K}\right)$ are necessary. The role of metastable species in affecting the chemistry of the atmosphere has not been seriously explored yet, largely because there are few measurements of reactions in which the states of the reacting species are identified.

Hunt (1966) has recently extended the original work of Bates and Nicolet (1950) on the photochemistry of an oxygen-hydrogen atmosphere and he has investigated in detail the diurnal variation of the ozone concentration. For a recent experimental investigation see Carver, Horton, and Burger (1966). Hunt's papers include a list of reaction rates. Of special interest is his demonstration that the metastable ${ }^{1} D$ atom of oxygen may play a significant role, despite its low concentration. Its importance appears to stem from the reaction

$$
\mathrm{O}\left({ }^{1} D\right)+\mathrm{H}_{2} \mathrm{O} \rightarrow \mathrm{OH}+\mathrm{OH}
$$

which leads to a source of free hydrogen atoms in the stratosphere. A major uncertainty in the calculation is the efficiency of deactivation of the metastable $\mathrm{O}\left({ }^{1} D\right)$ atoms. The ${ }^{1} D$ level is the upper level of the red line of atomic oxygen, the emission of which has been observed in the night and day airglow. The observed dayglow intensities are unexpectedly weak, since there are

* Paper prepared for International Astronomical Union Colloquium on Atomic Collision Processes, Boulder, Colorado, July 1966.

† Present address: Smithsonian Astrophysical Observatory and Harvard College Observatory, Cambridge, Mass. several large sources of $\mathrm{O}\left({ }^{1} D\right)$ atoms, such as photodissociation in the Schumann-Runge continuum of molecular oxygen, recombination of positive ions $\mathrm{O}_{2}+[\mathrm{but}$ probably not $\mathrm{NO}^{+}$(Dalgarno and Walker 1964)] and collisional excitation by the impact of nonthermal photoelectrons. The dayglow intensities apparently require a rate coefficient of $7 \times 10^{-11} \mathrm{~cm}^{3} \mathrm{sec}^{-1}$ for deactivation by collisions with the major constituent $\mathrm{N}_{2}$ :

$$
\mathrm{O}\left({ }^{1} D\right)+\mathrm{N}_{2} \rightarrow \mathrm{O}\left({ }^{3} P\right)+\mathrm{N}_{2} .
$$

The reaction scheme used by Hunt, with which he is able to reproduce the measured ozone profile, is based on a rate for (1) smaller by about two orders of magnitude.

The presence of $\mathrm{O}\left({ }^{1} D\right)$ atoms in the atmosphere may have important consequences on the nitrogen oxide chemistry also, but the rates of the possible reactions of $\mathrm{O}\left({ }^{1} D\right)$ atoms with the various nitrogen oxides (which are largely unknown) are necessary before a realistic analysis can be carried out.

The metastable species of molecular oxygen may also affect the hydrogen-oxygen chemistry and the nitrogen oxides chemistry. $\mathrm{O}_{2}$ molecules in the ${ }^{1} \Delta_{g}$ state are produced by a number of processes, the most abundant of which may be photodissociation in the Hartley continuum of ozone. The metastable molecules have been detected in the twilight and day airglow (Gattinger and Vallance Jones 1966). The production and loss mechanisms have been studied by Gattinger and Vallance Jones (1966) and by Schiff and Megill (1964), who draw attention to the possible effect of the reaction

$$
\mathrm{O}_{2}\left({ }^{1} \Delta_{g}\right)+\mathrm{O}_{3} \rightarrow \mathrm{O}_{2}+\mathrm{O}_{2}+\mathrm{O}
$$

on the ozone chemistry. Hunt (1966) has presented a list of some of the reactions involving $\mathrm{O}_{2}\left({ }^{1} \Delta_{g}\right)$ and $\mathrm{O}_{2}\left({ }^{1} \Sigma_{g}+\right)$, but the identification of the important reactions is tentative and the rate coefficients are very uncertain. Recent laboratory work on $\mathrm{O}_{2}\left({ }^{1} \Delta_{g}\right)$ has been reported by Badger, Wright, and Whitlock (1965).

The twilight emission of the $0-1 \mathrm{O}_{2}$ band of the ${ }^{1} \Delta_{g}-{ }^{3} \Sigma_{g}-$ system is much weaker than predicted and the theory does not explain the seasonal, annual, or evening-morning variations (Gattinger and Vallance Jones 1966).

The chemistry of the metastable ${ }^{1} \Delta_{g}$ states of $\mathrm{O}_{2}$ requires clarification in connection with a suggestion 
by Megill and Hasted (1965) that the detachment reaction

$$
\mathrm{O}_{2}\left({ }^{1} \Delta_{g}\right)+\mathrm{O}_{2} \rightarrow \mathrm{O}_{2}+\mathrm{O}_{2}+e
$$

may be significant in the $D$ region during a polar cap absorption event and possible also in the undisturbed $D$ region.

Associative detachment

$$
\mathrm{O}+\mathrm{O}_{2}^{-} \rightarrow \mathrm{O}_{3}+e
$$

may also be significant. The early theoretical suggestion that the rate coefficients may be as high as $10^{-10}$ $\mathrm{cm}^{3} \mathrm{sec}^{-1}$ have been confirmed by laboratory measurements of Fehsenfeld et al. (1967), who find that many associative detachment processes proceed with rates of about $10^{-10} \mathrm{~cm}^{3} \mathrm{sec}^{-1}$.

Analyses of $D$-region phenomena suggest that in practice detachment does not occur rapidly and it appears necessary to transform $\mathrm{O}_{2}^{-}$into a different negative ion which cannot participate in an efficient associative detachment process. A partial list of the relevant chemical reactions can be obtained from papers by Dalgarno (1961), Whitten and Popoff (1962), and Branscomb (1964).

It is now established that nitric oxide is an important constituent of the upper atmosphere, its ionization by solar Lyman-alpha being the principal source of electrons in the quiet upper $D$ region. Barth (1966) has detected NO by its fluorescence in the dayglow and he has determined a total abundance of $2.5 \times 10^{14} \mathrm{~cm}^{2}$ above $76 \mathrm{~km}$. The production of NO has been studied most recently by Nicolet (1965) and by Wagner (1966), who give a list of the reactions involved in the nitrogen oxides chemistry together with estimates of the rate coefficients. Further laboratory study of the reaction

$$
\mathrm{N}+\mathrm{O}_{2} \rightarrow \mathrm{NO}+\mathrm{O}
$$

would be valuable. It is sensitive to temperature and the conventional method of extrapolating the data to higher and lower temperatures may be misleading. Another source of NO is provided by the ionic reaction

$$
\mathrm{O}_{2}{ }^{+}+\mathrm{N}_{2} \rightarrow \mathrm{NO}^{+}+\mathrm{NO} \text {. }
$$

Upper limits to its rate coefficient have been derived from laboratory measurements (Galli, Giardini-Guidoni, and Volpi 1963, Ferguson, Fehsenfeld, Goldan, and Schmeltekopf 1965), but its actual value at $D$-region temperatures is unknown. Reaction (2) is also an important reaction in the chemistry of the ionic species, a subject which has been discussed most recently by Donahue (1966), who gives an extensive list of the chemical reactions affecting the major ions $\mathrm{O}^{+}, \mathrm{O}_{2}{ }^{+}$, $\mathrm{N}_{2}^{+}$, and $\mathrm{NO}^{+}$. Most of the relevant rate coefficients have been measured and reported in a series of papers, summarized by Ferguson et al. (1965) and Goldan et al. (1966), but usually only at room temperature. There is reasonable agreement between the theoretical and observed ion concentrations above $90 \mathrm{~km}$ (cf. Donahue 1966), but the position below $90 \mathrm{~km}$ is obscure. According to Donahue (1966), it is difficult to reconcile the reaction scheme selected for the $E$ and $F$. regions with the large $\mathrm{O}_{2}{ }^{+}$concentrations detected in the $D$ region by Narcissi and Bailey (1965). It may be noted that the metastable $\mathrm{O}_{2}+\left({ }^{4} \pi\right)$, which is produced in the atmosphere (Dalgarno and McElroy 1965), has been omitted from consideration. Little is known of the reactions responsible for its removal; they have been discussed briefly by Hunten and McElroy (1966), who have given a valuable, general review of deactivation processes in the atmosphere (see also Young and Black 1966). Reactions involving the metastable $\mathrm{O}^{+}\left({ }^{2} D\right)$ ion may also affect the ionic chemistry (Dalgarno and McElroy 1966).

A number of problems involving the identification of the reactions responsible are posed by the mass spectrometer measurements of Narcissi and Bailey (1965) (see also Narcissi 1966), who discovered that complex ions, consisting possibly of water-vapor clusters, are the dominant ionic species in the lower $D$ region.

However, the most serious difficulty in interpreting ionic composition in the ionosphere is probably that presented by the observed high abundance of positive helium ions in the topside ionosphere. The rate coefficients measured for

$$
\mathrm{He}^{+}+\mathrm{N}_{2} \rightarrow \mathrm{He}+\mathrm{N}_{2}{ }^{+}\left(\text {or } \mathrm{N}+\mathrm{N}^{+}\right. \text {) }
$$

(cf. Ferguson et al. 1965, Fehsenfeld et al. 1966) are apparently much too large (cf. Bauer 1966). Either there is an abundant source of $\mathrm{He}^{+}$as yet unrecognized or the measured rate coefficient is not applicable in ionospheric conditions. Stebbings, Rutherford, and Turner (1965) has suggested that the degree of vibrational excitation may be relevant, but further study is necessary. The process is also of interest in connection with the escape of neutral helium from the atmosphere and with the production at high altitudes of $\mathrm{N}_{2}{ }^{+}$ and $\mathrm{N}^{+}$ions.

The degree of vibrational excitation of the atmospheric molecules merits further study, especially since Schmeltekopf et al. (1967) have recently demonstrated in the laboratory that the rate of

$$
\mathrm{O}^{+}+\mathrm{N}_{2} \rightarrow \mathrm{NO}^{+}+\mathrm{N}
$$

increases rapidly with increasing vibrational temperature. This may be the explanation of the decrease in electron density in the vicinity of red arcs and during disturbed conditions. The vibrationally excited molecules can be produced by electron impact and possibly by the $\mathrm{O}\left({ }^{1} D\right)$ deactivation process (1).

It has been suggested (Potter and Del Duca 1960) that vibrational excitation may be the energy source for excitation of the Na $D$ lines according to

$$
\mathrm{Na}+\mathrm{N}_{2}{ }^{*} \rightarrow \mathrm{Na}\left({ }^{2} P\right)+\mathrm{N}_{2},
$$

and Hunten (1965) has obtained evidence that this 
reaction occurs in low altitude auroras. Recent laboratory work is described by Starr and Shaw (1966).

Experimental studies of vibrational excitation and de-excitation processes and of the effect of vibrational excitation on reaction rates would be of value. Bates (1955) has argued that the atom-atom interchange process

$$
\mathrm{O}+\mathrm{O}_{2} * \rightarrow \mathrm{O}_{2}+\mathrm{O}
$$

may be an efficient mechanism for deactivating $\mathrm{O}_{2}{ }^{*}$. If it is not, a substantial population of $\mathrm{O}_{2}{ }^{*}$ will occur in the atmosphere through production processes such as fluorescence in the discrete Schumann-Runge system. Apart from its effects on the atmospheric chemistry, $\mathrm{O}_{2}{ }^{*}$ can be ionized by solar radiation at longer wavelengths and the absorption of Lyman-alpha may be modified by its presence.

All of the reactions discussed so far are thermal collision processes. The nonthermal heavy particle collision processes which are of interest involve fast protons and the hydrogen atoms which result from electron capture by the protons in collisions with the atmospheric particles. The atmosphere is bombarded by protons during many auroras and in particular during polar cap auroras. Little information is available on the cross sections for the various possible processes beyond that given in Chamberlain's book (Chamberlain 1961), which discussed in detail the collision processes which occur (see also Prag, Morse, and McNeal 1966, Eather 1966).

The position is similar in the case of electron impact. Electron impact excitation and ionization studies have a new importance since photoelectrons contribute substantially to excitation of the dayglow, the successful observation of which (cf. Wallace and McElroy 1967) provides a valuable additional means of investigating atmospheric properties.

Electron collision processes determine also the electron and ion temperatures in the ionosphere. Most of the important processes are known to sufficient accuracy (cf. Dalgarno, McElroy, and Walker 1967), with the exception of vibrational and rotational excitation of molecular oxygen. Recent work on the cooling of electrons colliding with $\mathrm{O}_{2}$ is described in papers by Takayanagi (1965), Geltman and Takayanagi (1966), Mentzoni and Rao (1965), and Sampson and Mjolness (1966).

The success of the Mariner IV occultation experiment (Kliore et al. 1965) presents a number of problems of interpretation. The rates of reactions involving $\mathrm{CO}_{2}$ and its dissociation and ionization products are vital to a proper understanding of the structure of the Martian atmosphere. The ambient temperature may be very low and it is desirable to attempt measurements down to temperatures as low as $50^{\circ} \mathrm{K}$. The reaction

$$
\mathrm{O}^{+}+\mathrm{CO}_{2} \rightarrow \mathrm{O}_{2}^{+}+\mathrm{CO}
$$

is important for the Martian ionosphere. Its rate coefficient has been measured at room temperature (Fehsenfeld, Ferguson, and Schmeltekopf 1966, Paulson, Mosher, and Dale 1966), but not at $80^{\circ} \mathrm{K}$, the temperature suggested by Johnson (1965) and by Fjeldbo, Fjeldbo, and Eshleman (1966) as appropriate to the atmosphere at $120 \mathrm{~km}$. Chamberlain and McElroy (1966) argue that such low temperatures do not occur. Their argument rests on the assumption that $\mathrm{CO}_{2}{ }^{+}$ recombines rapidly with electrons and a measurement of the rate of dissociative recombination of $\mathrm{CO}_{2}{ }^{+}$ together with an identification of its end products is needed.

In discussing radiation losses, Chamberlain and McElroy (1966) assume that the rate coefficient for vibrational deactivation of $\mathrm{CO}_{2}$ varies with temperature $T$ as $\exp \left(-82.8 T^{-1 / 3}\right)$. The formula reproduces the high-temperature data adequately, but it is uncertain whether or not it remains appropriate over the possible range of Martian temperatures.

Because of the low densities prevailing in the Martian atmosphere, two-body collision processes assume a greater importance than in the terrestrial atmosphere, and radiative association, about which little quantitative information is available, may be the major recombination mechanism.

Of the other planets, there has been some discussion of the upper atmospheres of Venus (cf. Shimizu 1963), of Jupiter (cf. Gross and Rasool 1964), and of Mercury (Rasool, Gross, and McGovern 1966). Reactions involving the dissociation and ionization products of $\mathrm{CO}_{2}$ and $\mathrm{N}_{2}$ are significant for Venus and of $\mathrm{H}_{2}$ and $\mathrm{He}$ for Jupiter. Of particular relevance to a prediction of the composition of the ionosphere on Jupiter are the rates of the reactions

$$
\begin{aligned}
\mathrm{He}^{+}+\mathrm{H}_{2} & \rightarrow \mathrm{HeH}^{+}+\mathrm{H} \\
& \rightarrow \mathrm{He}+\mathrm{H}_{2}{ }^{+},
\end{aligned}
$$

which, though slow (Fehsenfeld et al. 1966), are probably responsible for the removal of $\mathrm{He}^{+}$ions.

\section{ACKNOWLEDGMENT}

This work has been partly supported by the GCA Corporation, Bedford, Mass.

\section{REFERENCES}

Badger, R. M., Wright, A. C., and Whitlock, R. F., 1965, J. Chem. Phys. 43, 4345 .

Barth, C., 1966, Ann. Géophys. 22, 198; and Planet. Space Sci. 14, 623.

Bates, D. R., 1955, J. Atmospheric Terrest. Phys. 6, 171.

Bates, D. R., and Nicolet, M., 1950, J. Geophys. Res. 55, 301. Bauer, S., 1966, Ann. Géophys. 22, 247.

Branscomb, L. M., 1964, Ann. Géophys. 20, 49.

Carver, J. H., Horton, B. H., and Burger, F. G., 1966, J. Geophys. Res. 71, 4189.

Chamberlain, J. W., 1961, Physics of the Aurora and Airglow (Academic Press Inc., New York).

Chamberlain, J. W., and McElroy, M. B., 1966, Science 152, 21. 
Dalgarno, A., 1961, Ann. Géophys. 17, 16.

Dalgarno, A., and McElroy, M. B., 1965, Planet. Space Sci. 13, 947.

Dalgarno, A., and McElroy, M. B., 1966, Planet. Space Sci. 14,1321 .

Dalgarno, A., McElroy, M. B., and Walker, J. C. G., 1967, Planet. Space Sci. 15, 331

Dalgarno, A., and Walker, J. C. G., 1964, J. Atmospheric Sci. 21, 463.

Donahue, T. M., 1966, Planet. Space Sci. 14, 33; and J. Geophys. Res. 71, 2237

Eather, R. H., 1966, J. Geophys. Res. 71, 4133.

Fehsenfeld, F. C., Ferguson, E. E., and Schmeltekopf, A. L., 1966, J. Chem. Phys. 44, 3022.

Fehsenfeld, F. C., Schmeltekopf, A. L., Goldan, P. D., Schiff, H. I., and Ferguson, E. E., 1966, J. Chem. Phys. 44, 4087.

Fehsenfeld, F. C., Schmeltekopf, A.L., Schiff, H. I., and Ferguson, E. E., 1967, Planet. Space Sci. 15, 373.

Ferguson, E. E., Fehsenfeld, F. C., Goldan, P. D., and Schmeltekopf, A. L., 1965, J. Geophys. Res. 70, 4323.

Fjeldbo, G., Fjeldbo, W. C., and Eshleman, V. R., 1966, J. Geophys. Res. 71, 2307.

Galli, A., Giardini-Guidoni, A., and Volpi, G. G., 1963, J. Chem. Phys. 38, 518

Gattinger, R. L., and Vallance Jones, A., 1966, Planet. Space Sci. 14, 1.

Geltman, S., and Takayanagi, K., 1966, Phys. Rev. 143, 25.

Goldan, P. D., Schmeltekopf, A. L., Fehsenfeld, F. C., Schiff, H. I., and Ferguson, E. E., 1966, J. Chem. Phys. 44, 4095.

Gross, S. H., and Rasool, S. I., 1964, Icarus 3, 311.

Hunt, B. G., 1966, J. Geophys. Res. 71, 1385.

Hunten, D. M., 1965, J. Atmospheric Terrest. Phys. 27, 503.

Hunten, D. M., and McElroy, M. B., 1966, Rev. Geophys. 4, 303.
Johnson, F. S., 1965, Science 150, 1445.

Kaufman, F., 1964, Ann. Géophys. 20, 106.

Kliore, A., Cain, D. L., Levy, G. S., Eshleman, V. R., and Fjeldbo, G., 1965, Science 149, 1243 .

Megill, L. R., and Hasted, J. B., 1965, Planet. Space Sci. 13, 339.

Mentzoni, M. H., and Rao, R. V. N., 1965, Phys. Rev. Letters 14,779 .

Narcissi, R. S., 1966, Ann. Géophys. 22, 224.

Narcissi, R. S., and Bailey, A. D., 1965, J. Geophys. Res. 70, 3687.

Nicolet, M., 1965, J. Geophys. Res. 70, 679 and 691.

Paulson, J. F., Mosher, R. L., and Dale, F., 1966, J. Chem. Phys. 44, 3025.

Potter, A. E., and Del Duca, B. S., 1960, J. Geophys. Res. 65, 3915.

Prag, A. B., Morse, F. A., and McNeal, R. J., 1966, J. Geophys. Res. 71, 3141.

Rasool, S. I., Gross, S. H., and McGovern, W. E., 1966, Space Sci. Rev. 5, 566.

Sampson, D. H., and Mjolness, R. C., 1966, Phys. Rev. 144, 116. Schiff, H. I., 1964, Ann. Géophys. 20, 115.

Schiff, H. I., and Megill, R. L., 1964, J. Geophys. Res. 69, 512.

Schmeltekopf, A. L., Fehsenfeld, F. C., Gilman, G. I., and Ferguson, E. E., 1967, Planet. Space Sci. 15, 401.

Shimizu, M., 1963, Planet. Space Sci. 11, 269.

Starr, W. L., and Shaw, T. M., 1966, J. Chem. Phys. 44, 4181.

Stebbings, R. F., Rutherford, J. A., and Turner, B. R., 1965, Planet. Space Sci. 13, 1125.

Takayanagi, K., 1965, Rept. Ionosphere Space Res. Japan 19, 1 Wallace, L., and McElroy, M. B., 1966, Planet. Space Sci. 14, 677.

Wagner, Chr.-Uhr., 1966, J. Atmospheric Terrest. Phys. 28, 607. Whitten, R. C., and Popoff, I. G., 1962, J. Atmospheric Sci. $21,17$.

Young, R. A., and Black, G., 1966, J. Chem. Phys. 44, 3741. 